\title{
How university presses are learning to serve digital humanists
}

\author{
Peter Berkery $^{\mathrm{a}, \mathrm{b}}$ and Annette Windhorn ${ }^{\mathrm{a}, \mathrm{b}, *}$ \\ ${ }^{a}$ Association of University Presses, 1412 Broadway, Suite 2135, New York, NY 10018, USA \\ ${ }^{\mathrm{b}} 1775$ Massachusetts Avenue NW, Washington, DC 20036, USA
}

\begin{abstract}
This paper is a brief history of university presses' efforts to collaborate with scholars and libraries to shape the digital humanities as we understand them today, focusing on four marquee projects: Rotunda, from the University of Virginia Press; Manifold, from the University of Minnesota Press; Fulcrum, from the University of Michigan Press and Libraries; and .supDigital, from Stanford University Press.
\end{abstract}

Keywords: digital humanities, digital scholarship, digital humanities publishing, university press publishing, digital humanities centers, Association of University Presses, Andrew W. Mellon Foundation, University of Virginia Press, Rotunda, University of Minnesota Press, Manifold, University of Michigan Press and Libraries, Fulcrum, Stanford University Press, .supdigital, Stanford Libraries, National Archives, National Endowment for the Humanities, American Council of Learned Societies, Society of Architectural Historians, digital publishing infrastructure, publishing services, born-digital, digitized, digital affordances, scalability, sustainability, archiving, archival, libraries

\section{Introduction}

At the NFAIS annual conference in February 2019, I offered a brief history of the efforts put forth by university presses to collaborate with scholars and libraries for the development of sustainable digital humanities projects. While there is no shortage of initiatives throughout our community that are worthy of mention, I chose to focus on four marquee projects and considered them chronologically, looking first at the early 2000s, then skipping ahead to 2015 . These four are:

- Rotunda, from the University of Virginia Press;

- Manifold, from the University of Minnesota Press;

- Fulcrum, from the University of Michigan Press and Libraries; and

- .supDigital, from Stanford University Press.

All of these projects have been generously and steadfastly supported by the Andrew W. Mellon Foundation, whose innovative funding priorities for at least the last two decades have helped shape the digital humanities field as we know it today.

\footnotetext{
*Corresponding author. E-mail: awindhorn@aupresses.org.
} 


\subsection{Rotunda (https://www.upress.virginia.edu/rotunda/about)}

Virginia's Rotunda is one of the university press community's oldest digital publishing projects and therefore valuable to consider as something of a longitudinal study as well as a vital ongoing endeavor. Created in 2001, predating common usage of the term "digital humanities", Rotunda originally worked with what were then called humanities computing centers or incubators (e.g., the Institute for Advanced Technology in the Humanities at the University of Virginia) to publish original digital scholarship along with newly-digitized critical and documentary editions in the humanities and social sciences. Rotunda applies traditional university press strengths in peer review, copyediting, design, marketing, and distribution to emerging research, and it uses the university press imprimatur to gain credit and recognition for the creators of this new form of scholarly output. Working at first with smaller, borndigital projects such as the Dolly Madison Digital Edition or Herman Melville's "Typee": A Fluid Text Edition, which likely could not have been sustainable on their own, Virginia's staff built a foundation for future efforts. They navigated the territory between the practice of digital humanities in a laboratory setting, giving rise to bespoke projects devoted to developing new tools, and the potential of applying rich metadata, natural language processing, embedded cross-references, and multimedia to larger corpora of texts, tagged in XML using best practices and loaded on a platform with robust search, navigation, and display. Throughout, they were mindful of scholars' desire for flexibility and interactivity, and libraries' need for platform standards (critical to archiving). In consultation with academic librarians, Rotunda developed and implemented a scalable, sustainable business model that combined a perpetual license with small annual hosting fees to support new content, enhancements, and updates to platform technology.

Rotunda today includes:

- A substantial American History Collection from three periods - Founding Era; Antebellum, Civil War, and Reconstruction; and the American Century - including eighteen digital documentary editions and a prosopographical ${ }^{1}$ dictionary as well as a parallel resource of six of the major Founding Fathers papers offered open access through a collaboration with the National Archives (NARA);

- A Literature and Culture Collection with seven projects ranging from born-digital comparative textual editions to legacy correspondence collections (e.g., Dickinson and Melville manuscript collections, George Herbert's verse in The Digital Temple); and

- The Society of Architectural Historians' Archipedia, an authoritative, peer-reviewed online encyclopedia of the built world, containing essays, building entries, photographs, and maps detailing more than twenty thousand structures and places in all fifty states. Assisted with grants from the National Endowment for the Humanities (NEH), this project extends the traditional online reference work into the realm of digital humanities by accommodating new entries, original articles, and dynamic data, as buildings change over time. In its first phase, SAH Archipedia offers free access to one hundred entries per state; a new responsive-design Archipedia will be released completely open access in the fall of 2019.

\subsection{Manifold (https://manifoldapp.org/ or https://manifold.umn.edu/)}

Minnesota's Manifold is an open-source, web-based publishing platform that can be used by scholarly publishers and scholars in university departments, digital humanities centers, and learned societies.

\footnotetext{
${ }^{1}$ https://www.thefreedictionary.com/prosopographical
} 
Developed with the Digital Humanities Lab at the Graduate Center of the City University of New York and Cast Iron Coding, the project seeks to assist authors whose work "can't fit between the covers of a book", as Inside Higher Education reporter Carl Straumsheim noted in April 2017 (see: https://www.insidehighered.com/news/2017/04/07/hybrid-publishing-platform-manifold-enters-publicbeta-phase).

A Manifold publication is composed of three parts:

- The base, text layer: for example, an EPUB file that a publisher uploads;

- A media layer: additional photos, videos, audio files, texts, or other media that an author or editor will add to the project; and

- A networking or interactive layer: reader comments, highlighting, and sharing, which make the works "alive" and iterative.

At this writing, twenty entities are currently working with Manifold: Minnesota and twelve other university presses - Athabasca University Press, the University of Arizona Press, the University of Cincinnati Press, the University Press of Colorado, Concordia University Press, Cornell University Press, the University Press of Florida, Indiana University Press, Liverpool University Press, Temple University Press, the University of Washington Press, and the University of the West Indies Press - as well as CUNY, Emory University, Reanimate Publishing Collective, and the University of Minnesota Libraries Publishing Services. Indiana University Press, for example, announced plans in March 2019 to digitally re-issue one hundred and sixty-three backlist titles via Manifold as part of the Humanities Open Book grant program supported by the Mellon Foundation and the NEH.

Although Manifold is free to use and can be installed on clients' own servers, Minnesota offers a few feebased services for those who prefer not to "do-it-yourself". Most of the groups currently using the platform have chosen to hire the Manifold team to host and maintain their sites, while handling the production work for the individual publications themselves.

\subsection{Fulcrum (https://www.fulcrum.org/)}

Michigan's Fulcrum encompasses a digital publishing infrastructure and a set of publishing services. It is committed to making scholarship available in a flexible, durable, discoverable, and accessible form. Fulcrum prioritizes these qualities:

- Flexibility: Working in partnership with the Samvera community (see: https://samvera.org/), Fulcrum connects to other open source tools and is responsive to the changing needs of digital scholars.

- Durability: Fulcrum is built on the University of Michigan Libraries' infrastructure, a trusted steward committed to preservation and stability.

- Discoverability: Fulcrum is interoperable with other publishing tools and integrated into the information supply chain.

- Accessibility: Fulcrum is dedicated to creating inclusive services and content for all readers.

In the past year, Fulcrum has published more than one thousand digital works from the University of Michigan Press, along with collections from several other university presses. Perhaps its most extensive partnership thus far has been with the American Council of Learned Societies (ACLS) on Humanities E-Books, which ACLS debuted as the History E-Book project in 2002 (with support from the Mellon Foundation) and which now encompasses more than fifty-four hundred titles, forty subject areas, and one 
hundred publishers (https://www.fulcrum.org/heb). The Fulcrum platform offers users of this collection an enriched web-native reading experience that is compatible with mobile devices and more easily navigable by institutional subscribers - including such features as page-turner, always-present table of contents, citation and search widgets, improved accessibility aligned with stringent WCAG 2.0 AA standards, and quick access to reviews, metadata, and statistics.

\section{4. .supDigital (https://www.sup.org/digital/)}

When Stanford University Press prepared to enter the digital publishing field, it focused on born-digital, interactive scholarly works. "Our goal is not to publish a book in digital form", says press director Alan Harvey. "Our goal is to publish digital scholarship in its native forms".

Stanford's digital publishing initiative applies the rigors of traditional university press publishing, especially peer review, to the digital medium. "We're looking for projects that use web technology to make arguments in novel ways" says digital humanities and computational social sciences editor Friederike Sundaram in a promotional video available on the press's blog. "Our goal is to support scholars who already are working in the computational medium to publish their work in the same medium in which they are conducting their research. We are focusing on projects that make arguments and offer interpretation, and they are united by being visually-driven, interactive, and multi-modal". For example, Stanford's pilot project in the initiative, Nicholas Bauch's Enchanting the Desert, pairs the photographs that popularized the Grand Canyon in the early twentieth century with cartography, critically evaluating this important national landscape.

One of the significant challenges that Stanford staff have taken on is to provide guidance to authors not only on the technology, but also on methods for embedding scholarly arguments within digital projects. After years of training on how to write journal articles and monographs, scholars across the academy are now experimenting with new tools and resources without any established standards. As a result, even these authors' peers can find it difficult to engage with such new research projects. Developing a new standard that builds upon and expands existing ones such as the monograph will ensure that this new work is recognizable and citable by peers.

Along the way, Stanford is developing best-practice guidelines for presentation, identifying preferred web authoring toolkits (such as Scalar and others), and designing a comprehensive archiving strategy that leverages Stanford Libraries' expertise and fosters key partnerships with other archiving and preservation groups in the academy.

\section{Lessons learned and path forward}

So, what do these four projects reveal about both how university presses are meeting the needs of digital humanists as well as expanding their own digital publishing capabilities?

First, let me acknowledge definitional issues inherent in the term "digital humanities". Some stakeholders define the term primarily in reference to the application of computational technology in the conduct of humanities research, while others focus on the digital affordances that technology is bringing to humanities scholarship and publishing. And, as noted above, university presses that are currently embracing digital humanities publishing are producing digitized print texts as well as born-digital projects. Consequently, my brief survey includes university press initiatives that support a broad range of what might be considered "digital humanities" - from primarily digital scholarly projects, to digitized humanities collections, to 
the creation of exciting digital affordances around a long-form scholarly argument or traditionally print documentary works.

The development of new technologies and ingenious thinking about digital humanities publishing has clearly been undergirded by grant funding - principally from the Andrew W. Mellon Foundation in the cases I've described, and also from the NEH and NARA. Visionaries in the university press community owe a particular debt to these supportive and forward-thinking organizations.

It's also clear that as experienced publishers, these university presses have brought a detailed understanding of publishing processes to bear on their priorities when exploring new digital modes:

- Each has upheld the fundamental value of peer review, in myriad and sometimes new forms, as foundational to the quality of mission-driven university press publishing.

- Each has worked with scholars to embrace the new synchronicities and flexibilities that publishing research digitally affords.

- Each has sought to develop and maintain standards that allow digital distribution of research to multiple reading devices as well as its archival storage and access for future generations.

- Each has remained mindful of the ultimate prizes of scalability and sustainability, not only by investing in smaller projects as stepping stones to larger, more complex ones, but also by identifying funding and infrastructure partners that ultimately will help them carry this work forward.

In the end, my whirlwind tour of these representative efforts reveals how an imaginative community of scholarly presses is applying its considerable expertise and timeless values to serve a new generation of scholars.

\section{Acknowledgements}

I wish to acknowledge and thank all who shared their insights with me for this presentation and article: Susan Doerr of the University of Minnesota Press, Alan Harvey and Friederike Sundaram of Stanford University Press, and Charles Watkinson of the University of Michigan Press and Libraries. I owe a special debt of gratitude to Mark Saunders of the University of Virginia Press, a visionary and true pioneer in the digital humanities as well as a respected leader in the AUPresses community, who passed away in May 2019.

\section{About the Author}

Peter Berkery has been Executive Director of the Association of University Presses (AUPresses) ${ }^{2}$ since early 2013. Peter came to AUPresses from Oxford University Press, where he served for the previous five years as Vice President and Publisher for the US Law Division. Prior to that he worked for Wolters Kluwer for 11 years in a series of positions, publishing works on securities licensing examination training, securities law, taxation, and financial planning. He began his publishing career at a division of Thomson Reuters.

Peter has extensive experience in government affairs and association management. He has been Director of Government Affairs for the National Society of Accountants and Government Relations Counsel for

\footnotetext{
${ }^{2}$ Formally established in 1937 as the Association of American University Presses (AAUP).
} 
the National Paint and Coatings Association, and has served as Assistant Executive Director and Staff Counsel for a division of the American Trucking Associations. He has served on the Board of Directors of the Accreditation Counsel for Accountancy and Taxation, and as its President.

Peter has a BA in Classical Studies from Boston College, and both an MA and a JD from The American University, as well as a Master of Laws in Taxation from George Washington University. He has been admitted to practice in Maryland, the District of Columbia, Hawaii, and the United States Tax Court. He is a certified financial planner. Email address: pberkery@aupresses.org. Correspondent: Annette Windhorn, Email address: awindhorn@aupresses.org. 